\title{
Human Umbilical Cord Stem Cells Regulate the Surrounding Microenvironment through Active Secretion of Signaling Molecules Kiran Kumar Velpula ${ }^{1}$ and Jasti S Rao ${ }^{1,2^{*}}$
}

${ }^{1}$ Department of Cancer Biology and Pharmacology, University of Illinois College of Medicine at Peoria, USA

${ }^{2}$ Department of Neurosurgery, University of Illinois College of Medicine at Peoria, USA

Human umbilical cord blood, a rich source of hematopoietic and mesenchymal stem cells, provides an interesting therapeutic source of primitive cells. Specifically, human umbilical cord blood stem cells (hUCBSC) involve neither ethical issues related to embryonic stem cells nor common serious side-effects such as graft-versus-host disease, which may occur with bone marrow stem cells. In addition, hUCBSC exhibit higher proliferation and expansion potential than their adult bone marrow counterparts [1]. Studies have demonstrated that hUCBSC influence their surrounding microenvironment in several ways: inhibiting neuronal death and apoptosis, controlling tumor proliferation and invasion, and inducing cell differentiation, neoangiogenesis, tissue repair and neuronal regeneration.

Earlier, we demonstrated that cell-to-cell contact plays an important role in the induction of apoptosis in glioma cells by hUCBSC [2]. However, more attention has recently been directed to the intercellular exchange of signaling molecules between stem cells and other surrounding cells. Studying the effect of hUCBSC on co-culturing with glioma cells, we collected microscopic evidence that strongly suggests an active outflow secretion from stem cells to surrounding media. Recently, we reported the effect of stem cells on matrix metalloproteinases, an important family of proteolytic enzymes involved in angiogenesis, inflammation and wound healing. In a spinal cord injury rat model, we demonstrated that hUCBSC treatment following spinal cord injury upregulates metalloproteinase-2 (MMP-2), reducing the formation of glial scar and thereby creating an environment suitable for endogenous repair mechanisms [3].

In addition to their important participation in angiogenesis, we demonstrated that MMPs contribute to cell migration. Utilizing a medulloblastoma tumor model, we observed that MMP-2 also mediates the tropism of hUCBSC to tumoral cells, and that MMP-2 inhibition is capable of repressing such stem cell tropism in an in vivo model [4]. Such interaction between hUCBSC and the surrounding environment may have profound effects on co-cultured glioma cells by attenuating uncontrolled cell cycle progression [5], inducing apoptosis, and reducing tumor migration [6].

The influence of the microenvironment upon stem cells has garnered special attention in recent years. Numerous studies argue that a class of molecules called chemokines (a subclass of chemotactic cytokines) are responsible for signaling and coordinating an important phenomenon called stem-cell 'homing' [7], in which stem cells are directed to tissues under critical conditions such as hypoxia [8], inflammation [9], irradiation [10] and tumoral growth [11]. Published literature suggests that these particular critical conditions dictate specific stem cell activity. For example, we observed that when coculturing with glioma cells, hUCBSC inhibit angiogenesis [12] while other scientists have demonstrated that stem cell transplantation after stroke induces angiogenesis [13]. Interestingly, recent studies have demonstrated that stem cells secretion may not be restricted to common intercellular paracrine factors, but might also involve other signaling molecules such as microvesicles containing microRNAs [14].
In summary, although cell-to-cell contact is one of the means by which stem cells regulate their surrounding environment, increasing evidence suggests that active secretion of signaling molecules from stem cells plays an important role in such interaction. Furthermore, recent evidence suggests that secretion involves not only the traditional cellular interaction including proteins and growth factors, but also intracellular signaling molecules such as microRNAs. The identification of such molecules as well as the proper understanding of the mechanism by which this interaction induces complex cellular processes, such as differentiation and apoptosis, poses a remarkable challenge to future molecular biologists.

\section{Acknowledgement}

This manuscript was prepared at the invitation of the Managing Editor of Brain Disorders \& Therapy.

\section{References}

1. Wang JC, Doedens M, Dick JE (1997) Primitive human hematopoietic cells are enriched in cord blood compared with adult bone marrow or mobilized peripheral blood as measured by the quantitative in vivo SCID-repopulating cell assay. Blood 89: 3919-3924.

2. Gondi CS, Gogineni VR, Chetty C, Dasari VR, Gorantla B, et al. (2010) Induction of apoptosis in glioma cells requires cell-to-cell contact with human umbilical cord blood stem cells. Int J Oncol 36: 1165-1173.

3. Veeravalli KK, Dasari VR, Tsung AJ, Dinh DH, Gujrati M, et al. (2009) Human umbilical cord blood stem cells upregulate matrix metalloproteinase-2 in rats after spinal cord injury. Neurobiol Dis 36: 200-212.

4. Bhoopathi P, Chetty C, Gogineni VR, Gujrati M, Dinh DH, et al. (2011) MMP-2 mediates mesenchymal stem cell tropism towards medulloblastoma tumors. Gene Ther 18: 692-701.

5. Velpula KK, Dasari VR, Tsung AJ, Gondi CS, Klopfenstein JD, et al. (2011) Regulation of glioblastoma progression by cord blood stem cells is mediated by downregulation of cyclin D1. PLoS One 6: e18017.

6. Dasari VR, Kaur K, Velpula KK, Gujrati M, Fassett D, et al. (2010) Upregulation of PTEN in glioma cells by cord blood mesenchymal stem cells inhibits migration via downregulation of the PI3K/Akt pathway. PLoS One 5: e10350.

7. Lapidot T, Petit I (2002) Current understanding of stem cell mobilization: the roles of chemokines, proteolytic enzymes, adhesion molecules, cytokines, and stromal cells. Exp Hematol 30: 973-981.

8. Das R, Jahr H, van Osch GJ, Farrell E (2010) The role of hypoxia in bone marrow-derived mesenchymal stem cells: considerations for regenerative medicine approaches. Tissue Eng Part B Rev 16: 159-168.

${ }^{*}$ Corresponding author: Jasti S.Rao, Department of Cancer Biology and Pharmacology, University of Illinois College of Medicine at Peoria, IL 61605, USA, Tel: 309-671-3445; E-mail: jsrao@uic.edu

Received May 19, 2012; Accepted May 21, 2012; Published May 24, 2012

Citation: Velpula KK, Rao JS (2012) Human Umbilical Cord Stem Cells Regulate the Surrounding Microenvironment through Active Secretion of Signaling Molecules. Brain Disord Ther 1:e102. doi:10.4172/2168-975X1000e102

Copyright: @ 2012 Velpula KK, et al. This is an open-access article distributed under the terms of the Creative Commons Attribution License, which permits unrestricted use, distribution, and reproduction in any medium, provided the original author and source are credited. 
Citation: Velpula KK, Rao JS (2012) Human Umbilical Cord Stem Cells Regulate the Surrounding Microenvironment through Active Secretion of Signaling Molecules. Brain Disord Ther 1:e102. doi:10.4172/2168-975X.1000e102

Page 2 of 2

9. Kavanagh DP, Kalia N (2011) Hematopoietic stem cell homing to injured tissues. Stem Cell Rev 7: 672-682.

10. Tabatabai G, Frank B, Möhle R, Weller M, Wick W (2006) Irradiation and hypoxia promote homing of haematopoietic progenitor cells towards gliomas by TGF-beta-dependent HIF-1alpha-mediated induction of CXCL12. Brain 129: 2426-2435.

11. Tabatabai G, Bähr O, Möhle R, Eyüpoglu IY, Boehmler AM, et al. (2005) Lessons from the bone marrow: how malignant glioma cells attract adult haematopoietic progenitor cells. Brain 128: 2200-2211.
12. Dasari VR, Kaur K, Velpula KK, Dinh DH, Tsung AJ, et al. (2010) Downregulation of Focal Adhesion Kinase (FAK) by cord blood stem cells inhibits angiogenesis in glioblastoma. Aging (Albany NY) 2: 791-803.

13. Horie N, Pereira MP, Niizuma K, Sun G, Keren-Gill H, et al. (2011) Transplanted stem cell-secreted vascular endothelial growth factor effects poststroke recovery, inflammation, and vascular repair. Stem Cells 29: 274-285.

14. Chen TS, Lai RC, Lee MM, Choo AB, Lee CN, et al. (2010) Mesenchymal stem cell secretes microparticles enriched in pre-microRNAs. Nucleic Acids Res 38 : 215-224. 